Management and Business Review, 1(2) 2017, 54-64

\begin{tabular}{|c|c|}
\hline $\mathrm{M} \mathbf{B R}$ & Management and Business Review \\
\hline $\begin{array}{r}\text { MANAGEMENT \& } \\
\text { BUSINESS REVIEW } \\
\end{array}$ & $\begin{array}{c}\text { Available at http://lejournal.unikama.ac.id/index.php/mbr } \\
\text { ISSN: } 2541-5808 \text { (online) }\end{array}$ \\
\hline
\end{tabular}

\title{
Pengaruh store atmosphere dan price discount terhadap keputusan pembelian impulse buying pelanggan Carrefour Market
}

\section{Irvan Eles Vilalba}

Program Studi Manajemen, Fakultas Ekonomika dan Bisnis, Universitas Kanjuruhan Malang, Indonesia

e-mail: eles irvan@yahoo.com

$\begin{array}{ll}\text { Article Info: } \\ \text { Receive } & \text { : Mei } 2017 \\ \text { Revised } & \text { : Juni } 2017 \\ \text { Accepted } & \text { : Juni } 2017 \\ \text { Published } & : \text { Juli } 2017 \\ \text { DOI } & : \text { 10.21067/mbr.vi2.4725 } \\ \text { Copyright } & : \text { Management and } \\ & \text { Business Review }\end{array}$

Keywords:

Store Atmosphere, Price Discount, Keputusan Pembelian Impulse Buying, Carrefour

\begin{abstract}
This study aims to determine the effect of store atmosphere and price discounts on impulse buying decisions of Carrefour Market customers. The research sample was 100 Carrefour Malang customers, which were taken randomly, the collection technique used a questionnaire, as for the multiple linear regression analysis technique. The results showed that store atmosphere had a positive and significant effect on impulse buying decisions, price discounts had a positive and significant effect on impulse buying decisions. The results of this study indicate that impulse buying behavior is created due to Carrefour's strategy in creating an attractive store atmosphere and price discount policies on several products sold.
\end{abstract}

\begin{abstract}
Abstrak: Penelitian bertujuan untuk mengetahui pengaruh store atmosphere dan price discount terhadap keputusan pembelian impulse buying pelanggan Carrefour Market. Sampel penelitian sebanyak 100 orang pelanggan Carrefour Malang, yang diambil secara acak, teknik pengumpulan menggunakan kuesioner, adapun teknik analisis Regresi Linear Berganda. Hasil penelitian menunjukkan bahwa store atmosphere berpengaruh positif dan signifikan terhadap keputusan pembelian impulse buying, price discount berpengaruh positif dan signifikan terhadap keputusan pembelian impulse buying. Hasil penelitian ini menunjukkan bahwa perilaku impulse buying tercipta karena strategi Carrefour dalam menciptakan store atmosphere yang menarik dan kebijakan price discount pada beberapa produk yang dijual.
\end{abstract}




\section{Pendahuluan}

Fenomena perkembangan zaman yang semakin modern, membuat kebutuhan manusia semakin meningkat pula dan seperti era perdagangan modern seperti saat ini, setiap perusahaan pasti menghadapi persaingan yang cukup ketat. Meningkatnya intensitas persaingan dan jumlah pesaing menuntut setiap perusahaan bersaing untuk memenuhi kebutuhan konsumen dengan cara yang lebih memuaskan daripada yang dilakukan oleh pesaingnya. Bagi peritel mengembangkan keunggulan kompetitif sangat diperlukan agar tidak kalah bersaing dengan kompetitor. Ritel merupakan sektor industri yang sangat populer dan sudah mendominasi kehidupan masyarakat Indonesia. Industri ritel (eceran) merupakan industri yang sangat strategis dan sangat menguntungkan karena existensinya tetap terjaga. Potensi pasar yang begitu besar, menarik peritel asing/modern untuk membuka gerainya di Indonesia dengan format hypermarket, supermarket dan minimarket, yang kini bertebaran di kota Malang. Gaya dan layanan ritel modern yang mewah dan elegan mampu dengan cepat menarik hati masyarakat untuk berbelanja di sana.

Perkembangan bisnis ritel modern juga merambah kota Malang karena Malang sendiri merupakan kota kedua terbesar di Propinsi Jawa Timur. Banyak sekali ritel modern yang ada di Kota Malang seperti Carrefour, Hypermart dan Giant. Dampak persaingan yang ketat dalam dunia ritel, hal ini akan mengakibatkan masing-masing ritel berlomba memberikan layanan terbaik kepada konsumen ataupun pelanggan.

Carrefour adalah sebuah kelompok supermarket internasional yang berkantor pusat di Perancis. Carrefour merupakan kelompok ritel kedua terbesar setelah Wal-Mart. Gerai Carrefour pertama dibuka pada 3 Juni, 1957, di Annecy di dekat sebuah persimpangan (Carrefour, dalam Bahasa Perancis). Kelompok ini didirikan oleh Marcel Founier dan Louis Deforey. Hingga Kini, gerai pertama ini adalah gerai Carrefour terkecil di dunia. Kelompok Carrefour memperkenalkan konsep hypermart untuk pertama kalinya, sebuah supermarket besar yang mengkombinasikan departement store (toko serba ada). Mereka membuka hypermarket pertamanya pada tahun 1962 di Sainte-Geneviene-des-Bos, dekat Paris, Perancis (www.infocarrefour.weebly.com).

Persaingan bisnis ritel pada saat ini mengharuskan setiap perusahaan untuk senantiasa melakukan strategi pemasaran agar dapat memenangkan persaingan yang kompetitif. Dasar penerapan strategi pemasaran adalah pemahaman perilaku belanja konsumen. Perilaku membeli memiliki dua macam pola (Loudon \& Bitta, dalam Kharis, 2011), yaitu pola pembelian yang berulang (brand loyality) dan pembelian tidak direncanakan (impulsive purchasing). Pada pola brand loyality, pembelian suatu produk oleh konsumen seringkali didasarkan pada merek tertentu. Hal tersebut seringkali berulang karena kesetiaan konsumen dengan merek tersebut 
sedangkan pada pembelian impulsive purchasing yaitu pembelian tidak direncanakan secara khusus. Kedua macam pola pembelian seperti inilah yang harus di pahami oleh peritel-peritel modern untuk membuat strategi-strategi dalam bisnis ritel sehingga ritel dapat bersaing dengan baik.

Berdasarkan dua macam pola diatas fenomena pembelian yang paling populer pada saat ini ialah perilaku belanja tidak terencana, karena perilaku pembelian tidak terencana merupakan perilaku konsumen yang unik dan tidak terduga dalam berbelanja. Selain itu dengan pembelian tidak terencana ritel juga dihadapkan dengan berbagai macam strategi agar pembelian seperti ini terus tercipta dari konsumen yang nantinya juga akan berpengaruh pada penjualan dalam ritel tersebut. Perilaku belanja tidak terencana adalah keputusan belanja yang dibuat oleh pelanggan secara spontan atau seketika setelah melihat barang dagangan (Utami, 2010). Faktor-faktor yang mempengaruhi perilaku belanja terencana ada dua yaitu dari internal dan eksternal. Dari internal terdiri dari suasana hati dan emosi positif, kebutuhan dan keinginan, emosional berbelanja, kognitif dan afektif. Sedangkan dua faktor eksternal berupa stimulus-stimulus yang diciptakan peritel di dalam lingkungan toko (Karbasivar \& Yarahmadi, 2011).

Salah satu faktor eksternal yang diciptakan peritel ialah atmosfer gerai. Atmosfer yang di tonjolkan di dalam toko merupakan trik pemasar ritel untuk menarik konsumen untuk berbelanja. Salah satu penyebab terjadinya pembelian impulsif ialah pengaruh stimulus dari tempat belanja tersebut (Christina, 2006). Dalam bisnis yang kompetitif saat ini, atmosfer toko dianggap sebagai salah satu hal yang penting bagi toko ritel. Suasana toko merupakan salah satu bagian dari bauran eceran yang memiliki arti yang sangat penting dalam manjalankan bisnis ritel (Gillani, 2012). Dengan adanya suasana toko yang baik, maka akan menarik konsumen untuk melakukan pembelian. Store atmosphere mempengaruhi keadaan emosi pembeli yang menyebabkan atau mempengaruhi pembelian (Theresia, 2014).

Faktor kedua dari eksternal ritel yang di jadikan varibel dalam penelitian ini ialah diskon harga. Informasi mengenai suatu gerai dapat diketahui dari aktifitas pemasaran yang dilakukan perusahaan melalui promosi. Strategi promosi merupakan salah satu dari bauran pemasaran ritel yang sangat penting. Salah satunya ialah dengan diskon harga yang ditawarkan di toko tersebut. Harga diskon adalah strategi promosi penjualan yang paling banyak digunakan baik online maupun offline (Chen et al., 2012). Harga diskon adalah strategi promosi penjualan berbasis harga di mana pelanggan kembali ditawarkan produk yang sama dengan harga berkurang. Harga diskon dapat ditawarkan sebagai pengurangan dalam hal persentase dari harga asli. Menurut Kotler \& Keller (2009), potongan harga adalah diskon langsung dari harga untuk masing-masing produk yang dibeli selama kurun waktu yang telah disebutkan. Seperti halnya perusahaan lainya promosi memang sangat penting karena untuk menawarkan produknya agar segera diminati oleh pelanggan. Menurut Kurniawan (2013) jika promosi ditingkatkan, maka impulse 
buying akan meningkat. Hasil penelitian yang dilakukan oleh Banerjee \& Saha (2012) menemukan bahwa kegiatan promosi melalui potongan harga dan diskon memicu terjadinya pembelian impulse.

Menyadari pentingnya sebuah strategi pemasaran sehingga konsumen melakukan pembelian tidak terencana disuatu toko, maka penulis sangat tertarik untuk mengkaji lebih dalam mengenai faktor-faktor dan strategi apa saja yang harus dilakukan oleh pihak perusahaan dalam hal ini adalah Carrefour. Tujuan dilakukannya penelitian ini adalah untuk mengetahui seberapa jauh store atmosphere Carrefour Blimbing Malang memberikan pengaruh terhadap konsumen dan pelanggan dalam berbelanja impulse buying dan untuk mengetahui bagaimana pengaruh pelanggan yang di dapat dari penawaran price discount dalam pembelian impulse buying di Carrefour Blimbing Malang.

\section{Keputusan Pembelian Impulse Buying}

Perilaku pembelian tidak terencana (unplanned buying) merupakan perilaku pembelian yang dilakukan dalam toko, dimana pembelian tidak sesuai dengan perencanaan pembelian konsumen ketika masuk ke dalam toko. Pembelian tidak terencana adalah suatu tindakan pembelian yang dibuat tanpa direncakan dulu sebelumnya pada saat berada di dalam toko. Engel et al. (1994) mendefinisikan impulse buying adalah pembelian yang terjadi ketika konsumen mengalami perasaan tiba-tiba, penuh kekuatan dan dorongan yang kuat untuk membeli sesuatu dengan segera. Sedangkan dalam Solomon et al. (2012) kecenderungan untuk membeli secara spontan ini umumnya dapat menghasilkan pembelian ketika konsumen percaya bahwa tindakan tersebut adalah hal yang wajar. Pembelian tidak terencana bisa terjadi ketika konsumen tidak familier dengan tata ruang toko, dibawah tekanan waktu, atau seseorang teringat akan kebutuhan untuk membeli ketika melihat pada rak di toko. Menurut penelitian (Rachmawati, 2009) pembelian berdasar impulse mungkin memiliki satu atau lebih karakteristik: spontanitas, kekuatan kompulasi, dan intensitas, kegairahan dan stimulasi, ketidakpedulian akan akibat.

Desakan untuk membeli dapat menjadi begitu sulit ditolak sehingga akibat yang mungkin negatif diabaikan. Dengan dasar penjelasan di atas dapat disimpulkan bahwa impulse buying merupakan kegiatan berbelanja tanpa kontrol diri atau tanpa perimbangan mendalam. Dengan alasan pengalaman emosional lebih daripada rasional. Sehingga kebanyakan pembelian pada barang barang yang tidak diperlukan pada saat itu juga.

\section{Store Atmosphere}

Menurut Christina (2006) mendefinisikan store atmosphere merupakan kombinasi dari karakter fisik gerai seperti arsitektur, layout, pengaturan pencahayaan, display, pemaduan warna, suhu, alunan musik dan aroma yang 
menyeluruh. Melalui suasana toko yang sengaja diciptakan oleh ritel, ritel berupaya untuk mengkomunikasikan informasi yang terkait dengan layanan, harga maupun ketersediaan barang dagangan yang bersifat fashionable. Atmosfer gerai merupakaan bagian terpenting dari ritel mix yang mampu mempengaruhi keputusan pembelian konsumen. Atmosfer berperan penting dalam menarik minat pembeli, memberikan kenyamanan saat memilih barang belajaan, dan mengingatkan pada mereka produk yang perlu dibeli baik digunakan untuk keperluan pribadi maupun keperluan rumah tangga (Ma'ruf, 2006). Respon konsumen tidak hanya sebatas pada produk barang atau jasa yang ditawarkan melainkan terhadap lingkungan gerai yang di ciptakan.

Donovan dan Rossiter dalam Peter \& Olson (2000) mengemukakan suasana toko (store atmosphere) yang melibatkan afeksi dalam bentuk emosi dalam gerai yang kemungkinan tidak disadari sepenuhnya oleh konsumen ketika sedang berbelanja. Menurut Berman \& Evans (2005) bagi gerai yang merupakan basic ritailer atau eceran, suasana lingkungan gerai dinilai berdasarkan karakteristik fisik yang digunakan untuk menarik konsumen. Atmosfer gerai dapat memberikan dorongan kepada konsumen untuk datang kembali, membangkitkan kesenangan dalam berbelanja, serta akan meluangan waktu lebih lama untuk berada didalam gerai.

Atmosphere mengacu pada desain sebuah lingkungan dengan stimulasi pancaindera. Suasana lingkungan toko yang diciptakan paritel mengomunikasikan segala informasi untuk memudahkan konsumen. Berikut ini yang berpengaruh pada keadaan toko (Levy \& Weitz, 2004) yaitu desain toko, tata letak toko, komunikasi visual, penerangan, warna, musik, aroma.

\section{Price Discount}

Diskon atau potongan harga merupakan salah satu bentuk dari promosi penjualan yang sering diterapkan oleh pemasar yang lebih ditujukan kepada konsumen akhir. Konsumen menyukai diskon karena konsumen mendapat pengurangan kerugian dari potongan harga langsung dari suatu produk (Lowe, 2010). Diskon tersebut merupakan harga yang populer karena merangsang langsung pembelian produk yang dipromosikan, sehingga terjadi peningkatan penjualan (Gendall et al., 2006). Campo \& Yagüe (2007) mendefinisikan discount sebagai berikut, discount adalah penurunan harga dari harga yang dipublikasikan, yang dapat konsumen bandingkan dengan informasi harga yang telah diketahui oleh konsumen.

Penelitian sebelumnya di Indonesia telah menguji faktor-faktor yang mempengaruhi pembelian impulsif, seperti penelitian Pemayun \& Ekawati (2016) tentang pengaruh promosi, atmosfer gerai, dan merchandise terhadap pembelian impulsif pada Hardy's Mall Gatsu di Denpasar, hasil penelitian menunjukkan bahwa promosi, atmosfer gerai dan merchandise berpengaruh positif dan signifikan terhadap pembelian impulsif pelanggan Hardy's Mall Gatsu Denpasar. Selanjutnya 
penelitian Gumilang \& Nurcahya (2016) tentang pengaruh price discount dan store atmosphere terhadap emotional shopping dan impulse buying. Hasil penelitian menunjukkan bahwa Emotional Shopping memiliki pengaruh secara langsung terhadap Impulse Buying, variabel Price Discount memiliki pengaruh secara langsung terhadap variabel Emotional Shopping, variabel Store Atmosphere memiliki pengaruh secara langsung terhadap variabel Emotional Shopping, variabel Price Discount memiliki pengaruh secara langsung terhadap variabel Impulse Buying, variabel Store Atmosphere memiliki pengaruh secara langsung terhadap variabel Impulse Buying.

Penelitian Pradipta \& Rastini (2014) tentang pengaruh atmosfer toko, promosi penjualan, dan interaksi antara karyawan toko dengan pembeli tehadap keputusan impulse buying di Carrefour Hypermarket, hasilnya menunjukkan bahwa atmosfer toko, promosi penjualan, dan interaksi antara karyawan dengan pembeli mempengaruhi keputusan impulse buying di Carrefour Hypermarket. Penelitian Asterrina \& Hermiati (2013) tentang pengaruh discount terhadap perilaku impulse buying pada konsumen Centro Departement Store Dimargo City. Dari hasil analisis menunjukan pengaruh indikator-indikator dari variabel Discount terhadap variabel Impulse Buying adalah kuat, persepsi konsumen pada discount memberikan kontribusi pengaruh terhadap perilaku impulse buying.

H1: Ada pengaruh positif dan signifikan antara store atmosphere terhadap keputusan pembelian impulse buying di Carrefour Market Blimbing Malang.

H2: Ada pengaruh positif dan signifikan antara price discount terhadap terhadap keputusan pembelian impulse buying di Carrefour Market Blimbing Malang.

\section{Metode}

Penelitian menggunakan rancangan sebab akibat atau kausal yang terdiri dari 3 variabel yaitu variabel independen $(X)$ yang diukur melalui Store Atmosphere dan Price Discount serta variabel dependen (Y) adalah variabel yang diukur melalui keputusan pembelian impluse buying di Carrefour Blimbing Kota Malang.

Penelitian dilakukan pada konsumen Carrefour Market Blimbing yang berbelanja dan pernah belanja, tepatnya di Jl. A. Yani No. 2A Kota Malang. Teknik pengambilan sampel yang dipilih dalam penelitian ini adalah dengan menggunakan cara non-probability sampling dengan metode accidental sampling, yaitu peneliti memilih responden dengan cara mendatangi responden di Carrefour lalu memilih calon responden yang secara kebetulan ditemui namun calon responden harus memiliki karakteristik tertentu, yaitu responden yang melakukan pembelian lebih dari satu kali di Carrefour Market Blimbing Malang dan melakukan pembelian dengan tidak ada rencana sebelumnya (impulse buying) dan dia membeli dengan jenis-jenis dan macam-macam produk dalam trolly/keranjang belanjanya. Dalam penelitian ini digunakan metode pengumpulan data menggunakan Kuesioner (Angket). 
Penilaian terhadap variabel yang diidentifikasi tentang pengaruh Store Atmosphere dan Discount Price terhadap keputusan pembelian implusif buying dilakukan dengan pernyataan berskala. Dalam kuisioner ini digunakan skala Likert 1-5. Dalam penelitian ini digunakan rentang penilaian 1 sampai dengan 5 di mana nilai 1 dikategorikan ukuran penilaian sangat tidak setuju (STS), nilai 2 menunjukkan ukuran penilaian tidak setuju (TS), nilai 3 menunjukkan ukuran penilaian netral $(\mathrm{N})$, nilai 4 menunjukkan ukuran penilaian setuju (S), dan nilai 5 menunjukkan ukuran penilaian sangat setuju (SS). Dalam penelitian ini penulis menggunakan metode regresi linier berganda, yaitu suatu metode statistik yang digunakan untuk mengetahui hubungan antara variabel bebas dan terikat. Model regresi adalah model yang digunakan untuk menganalisis pengaruh dari beberapa variabel independen terhadap satu variabel.

Teknik analisis data menggunakan Regresi Linier berganda, yaitu suatu metode statistik yang digunakan untuk mengetahui hubungan antara variabel bebas dan terikat. Jenis data yang digunakan dalam penelitian adalah data kuantitatif yang diolah menggunakan program SPSS. 20.0 for Windows.

\section{Hasil}

\section{Analisis Regresi}

Analisis data penelitian menggunakan Regresi Linear Berganda, untuk menguji pengaruh variabel bebas terhadap variabel terikat. Untuk menjamin hasil analisis tidak bias perlu dilakukan asumsi klasik. Hasil pengujian asumsi normalitas menunjukkan bahwa data memenuhi syarat distribusi normal, selanjutnya untuk uji asumsi multikolinieritas diperoleh setiap variabel bebas mempunyai nilai nilai VIF < 10 yaitu 1,139, Jadi dapat tidak ada multikolinieritas antar variabel bebas dalam model regresi ini. Hasil scatterplot terlihat bahwa titik-titik menyebar secara acak serta tersebar baik di atas maupun dibawah angka 0 pada sumbu $Y$, hal ini dapat disimpulkan tidak terjadi heteroskedastisitas pada model regresi ini. Ringkasan hasil analisis regresi disajikan pada tabel 1.

Nilai koefisien regresi variabel store atmosphere sebesar 0,199 artinya apabila variabel store atmosphere meningkat, maka keputusan pembelian impulse buying juga meningkat, sebaliknya apabila variabel store atmosphere menurun, maka keputusan pembelian impulse buying juga menurun. Nilai koefisien regresi pada variabel price discount sebesar 0,416 artinya apabila variabel price discount meningkat, maka keputusan pembelian impulse buying juga meningkat, sebaliknya apabila variabel price discount menurun, maka keputusan pembelian impulse buying juga menurun. 
Tabel 1

Hasil Analisis Regresi Berganda

\begin{tabular}{|c|c|c|c|c|c|}
\hline \multicolumn{2}{|c|}{ Variabel Bebas } & B & $\mathrm{T}$ & Prob. & Keterangan \\
\hline \multicolumn{2}{|c|}{ Store Atmosphere $(\mathrm{X} 1)$} & 0,199 & 3,242 & 0,002 & Signifikan \\
\hline \multicolumn{2}{|c|}{ Price Discount $(\mathrm{X} 2)$} & 0,416 & 9,382 & 0,000 & Signifikan \\
\hline \multicolumn{6}{|c|}{ Variabel Terikat: Keputusan Pebelian Impulse Buying(Y) } \\
\hline \multicolumn{6}{|c|}{ Konstanta $=11,175$} \\
\hline $\mathrm{R}$ & \multicolumn{5}{|l|}{$=0,765$} \\
\hline R Square & \multicolumn{5}{|l|}{$=0,584$} \\
\hline \multicolumn{6}{|c|}{ Adjusted $\mathrm{R}$ Square $=0,576$} \\
\hline $\mathrm{F}$ & \multicolumn{5}{|l|}{$=68,217$} \\
\hline $\operatorname{Sig} \mathrm{F}$ & \multicolumn{5}{|l|}{$=0,000$} \\
\hline
\end{tabular}

Sumber: Data diolah, (2017)

Hasil uji $\mathrm{R}^{2}$ pada penelitian ini diperoleh nilai $\mathrm{R}^{2}$ sebesar $0,576=57,6 \%$. Hal ini menunjukkan bahwa keputusan pembelian impulse buying dipengaruhi oleh store atmosphere dan price discount sebesar 57,6\%, sedangkan sisanya sebesar 42,4\% dipengaruhi oleh faktor lain yang tidak termasuk dalam penelitian ini.

\section{Uji Hipotesis}

Store Atmosphere

Hasil statistik uji $t$ untuk variabel store atmosphere diperoleh nilai $t$ hitung sebesar 3,242 dan $\mathrm{t}$ tabel 1,984 ( $\mathrm{df}=100)$ dengan tingkat signifikansi 0,002. karena $\mathrm{t}$ hitung $>\mathrm{t}$ tabel $(3,242>1,984)$, signifikansi lebih kecil dari $0,05(0,002<0,05)$, dan koefisien regresi mempunyai nilai positif sebesar 0,199 maka hipotesis pengujian tersebut menolak Ho dan menerima Ha sehingga H1 yang menyatakan ada pengaruh positif dan signifikan store atmosphere terhadap keputusan pembelian impulse buying diterima.

Price Discount

Hasil statistik uji $\mathrm{t}$ untuk variabel price discount diperoleh nilai $\mathrm{t}$ hitung sebesar 9,382 dan $\mathrm{t}$ tabel 1,984 ( $\mathrm{df}=100)$ dengan tingkat signifikansi 0,000 . karena $\mathrm{t}$ hitung $>$ t tabel $(9,382>1,984)$, signifikansi lebih kecil dari $0,05 \quad(0,000<0,05)$, dan koefisien regresi mempunyai nilai positif sebesar 0,416 maka hipotesis pengujian tersebut menolak Ho dan menerima Ha sehingga H1 yang menyatakan ada pengaruh positif dan signifikan price discount terhadap keputusan pembelian impulse buying diterima.

\section{Pembahasan}

Berdasarkan hasil analisis dan uji hipotesis mengenai pengaruh store atmosphere dan price discount terhadap keputusan pembelian impulse buying pada 
pelanggan di Carrefour Market Blimbing Malang dijelaskan bahwa hipotesis menunjukkan bahwa variabel store atmosphere berpengaruh positif signifikan secara parsial terhadap impulse buying dimana semakin baik penciptaan suasana store atmosphere yang dilakukan Carrefour Market Blimbing Malang maka akan dapat meningkatkan impulse buying yang dilakukan pelanggan. Hasil pengujian hipotesis menunjukkan bahwa variabel price discount berpengaruh positif signifikan secara parsial terhadap impulse buying dimana semakin banyak diskon yang diberikan di Carrefour Market Blimbing Malang maka akan dapat meningkatkan impulse buying yang dilakukan pelanggan.

Temuan penelitian ini mendukung beberapa penelitian terdahulu yang menyatakan bahwa store atmosphere berpengaruh positif terhadap impulse buying (Gumilang \& Nurcahya, 2016; Pemayun \& Ekawati, 2016; Pradipta \& Rastini, 2014), yang semuanya berpendapat bahwa store atmosphere adalah faktor yang mempengaruhi impulse buying. Temuan terkait price dicount mempengaruhi impulse buying mendukung penelitian dari Gumilang \& Nurcahya (2016), price discount akan menyebabkan terjadinya peningkatan penjualan (Gendall et al., 2006).

\section{Simpulan}

Hasil analisis dan pengujian hipotesis dalam penelitian ini, kesimpulan yang diperoleh adalah terdapat pengaruh positif dan signifikan store atmosphere terhadap keputusan pembelian impulse buying pada pelanggan di Carrefour Market Blimbing Malang. Price discount berpengaruh positif dan signifikan terhadap keputusan pembelian impulse buying pada pelanggan di Carrefour Market Blimbing Malang. Kepada para peneliti selanjutnya sebaiknya menggunakan variabel yang lain yang paling berpengaruh secara menyeluruh agar dapat tercipta generalisasi teori tentang faktor-faktor yang mempengaruhi impulse buying.

\section{Daftar Pustaka}

Asterrina, F., \& Hermiati, T. (2013). Pengaruh discount terhadap perilaku impulse buying. E-Jurnal Administrasi Niaga, 7.

Banerjee, S., \& Saha, S. (2012). Impulse buying behaviour in retail stores-Triggering the senses. Asia Pacific Journal of Marketing \& Management Review, 1(2), 1-21.

Berman, B., \& Evans, J. R. (2005). Retail Management a strategic approach. Pearson.

Campo, S., \& Yagüe, M. J. (2007). Effects of price promotions on the perceived price. International Journal of Service Industry Management.

Chen, H., Marmorstein, H., Tsiros, M., \& Rao, A. R. (2012). When more is less: The 
impact of base value neglect on consumer preferences for bonus packs over price discounts. Journal of Marketing, 76(4), 64-77.

Christina, W. U. (2006). Manajemen Ritel (Strategi dan Implementasi Ritel Modern). Jakarta: Salemba Empat.

Engel, J. F., Blackwell, R. D., \& Miniard, P. W. (1994). Perilaku Konsumen. Jakarta: Binarupa Aksara.

Gendall, P., Hoek, J., Pope, T., \& Young, K. (2006). Message framing effects on price discounting. Journal of Product $\mathcal{E}$ Brand Management.

Gillani, F. (2012). Impact of peer pressure and store atmosphere on purchase intention: An empirical study on the youngsters in Pakistan. International Journal of Academic Research in Business and Social Sciences, 2(7), 323.

Gumilang, W. A., \& Nurcahya, I. K. (2016). Pengaruh Price Discount Dan Store Atmosphere Terhadap Emotional Shopping Dan Impulse Buying. E-Jurnal Manajemen Universitas Udayana, 5(3).

Karbasivar, A., \& Yarahmadi, H. (2011). Evaluating effective factors on consumer impulse buying behavior. Asian Journal of Business Management Studies, 2(4), 174181.

Kotler, P., \& Keller, K. L. (2009). Manajemen Pemasaran. Jakarta: Erlangga.

Kurniawan, D. (2013). Pengaruh promosi dan store atmosphere terhadap impulse buying dengan shopping emotion sebagai variabel intervening studi kasus di Matahari department store cabang supermall Surabaya. Jurnal Strategi Pemasaran, 1(2), 1-8.

Levy, M., \& Weitz, B. A. (2004). Retailing management. McGraw-Hill/Irwin.

Lowe, B. (2010). Consumer perceptions of extra free product promotions and discounts: the moderating role of perceived performance risk. Journal of Product and Brand Management, 19(7), 496-503.

Ma'ruf, H. (2006). Pemasaran ritel. Gramedia Pustaka Utama.

Pemayun, T. I. D. P., \& Ekawati, N. W. (2016). Pengaruh Promosi, Atmosfer Gerai, dan Merchandise terhadap Pembelian Impulsif pada Hardy's Mall Gatsu Denpasar. E-Jurnal Manajemen Universitas Udayana, 5(7).

Peter, J. P., \& Olson, J. C. (2000). Consumer behavior: Perilaku konsumen dan strategi pemasaran. Jakarta: Erlangga.

Pradipta, I. N. M. A. W., \& Rastini, N. M. (2014). Pengaruh Atmosfer Toko, Promosi Penjualan, Dan Interaksi Antara Karyawan Toko Dengan Pembeli Terhadap Keputusan Impulse Buying Di Carrefour Hypermarket. E-Jurnal Manajemen Universitas Udayana, 3(8). 
Rachmawati, V. (2009). Hubungan antara hedonic shopping value, positive emotion, dan perilaku impulse buying pada konsumen ritel. Jurnal Ekonomi Dan Bisnis Airlangga (JEBA)| Journal of Economics and Business Airlangga, 19(2).

Solomon, M., Russell-Bennett, R., \& Previte, J. (2012). Consumer behaviour. Pearson Higher Education AU.

Theresia, V. M. (2014). Faktor-Faktor Yang Memengaruhi Pembelian Impulsif Pada Remaja Gereja GMIM Wilayah Manado Winangun (studi di Manado Town Square). Jurnal Riset Bisnis Dan Manajemen, 2(4).

www.infocarrefour.weebly.com 